\title{
High Affinity Nerve Growth Factor Receptor Isoform TrkA-III
}

National Cancer Institute

\section{Source}

National Cancer Institute. High Affinity Nerve Growth Factor Receptor Isoform TrkA-III. NCl Thesaurus. Code C105368.

High affinity nerve growth factor receptor isoform TrkA-III (698 aa, 77 kDa) is encoded by the human NTRK1 gene. This protein is involved in constitutive signaling and tyrosine phosphorylation. 